\section{Advanced Technology Program}

SIR - Your leading article "Surrender on technology support" (Nature 380, 185; 1996) accurately points out that, in a time of tight budget constraints, there is no place for the Advanced Technology Program (ATP) in the US federal budget.

What is erroneous, however, is the characterization of comments I have made about the link between the awarding of ATP grants and political contributions, where you describe my claim that grants are being used as political patronage as "an unsubstantiated slur" on staff at the National Institute of Standards and Technology (NIST). A policy analysis entitled Ending Corporate Welfare As We Know It, written by Stephen Moore and Dean Stansel of the Cato Institute and released in May 1995, states:

Many of the top recipients of technology research grants awarded by the Clinton administration were also substantial contributors to the Clinton campaign or the Democratic National Committee. For example, Table 1 [on page 8 of the study] lists eight Fortune 500 firms that were multi-million-dollar award winners of the Advanced Technology Program or the Technology Reinvestment Project in 1994 that were also large Democratic campaign contributors, according to Federal Election Commission (FEC) data compiled by Common Cause. At the very least, these golden handshake programs create an impression that government is for sale.

NIST is a vital part of the federal science infrastructure of the United States. The scientists carrying out basic research at the NIST laboratories are topnotch and should be commended for their work. The real slur on these employees is the Clinton administration's budget request for fiscal year 1997. While the administration continues to request money for ATP, the president's request for the scientific and technical research and services, known as the NIST "core", was lower this year than last.

Robert S. Walker

(Chairman)

Committee on Science,

US House of Representatives,

Washington DC 20515, USA

SIR - You characterize the US Commerce Department's Advanced Technology Program (ATP) as "an expensive act of faith". Without wishing to get into a theological debate, there are some significant leaps of faith - well, perhaps "leaps of doubt" - in your argument.

You say "no-one will ever know" if the ATP achieves its objective of significantly enhancing the US economy by enabling industry to develop economically important but high-risk technologies. In fact, we will almost certainly have a much better understanding of the actual impact of the ATP on industry and the US economy than for virtually any other comparable programme in either the public or private sectors.

We agree that government programmes, particularly funding programmes like the ATP, should be monitored carefully and evaluated. The ATP has emphasized rigorous measurement and evaluation of its procedures from the start. These range from periodic surveys and a sophisticated business reporting system to track the progress of individual projects to detailed case studies and econometric analyses to help project impacts from individual companies to an industry or the economy as a whole. In addition to its own in-house staff of business and economic experts, the ATP regularly consults leading academic economists to develop state-of-the-art methodologies for measuring programme impact.

Indeed, while it is clearly premature to talk about the long-term effects of the ATP, short-term effects have been well documented. Companies have committed approximately $\$ 1$ billion of their own funds to research projects that by their own analyses would not have been attempted, or would have been pursued at a significantly lower level of effort, without the ATP. Research and development schedules have been accelerated significantly. Early ATP projects are already resulting in business growth because of the availability of new technologies. More companies are establishing mutually beneficial research and development alliances with customers, suppliers and even competitors as a result of the ATP. All of these trends augur well for the programme's long-range impact.

You argue that, as an experiment, the ATP has no "accepted" design, no endpoints, and no control. True, we can't run a control version of the United States without the ATP. By that facetious standard, virtually no government programme including support for basic research - and precious few private enterprises would ever be pursued.

You feel that it will be difficult to justify the Clinton administration's insistence on the ATP "at a time when the US government has no money for the excellent university science funded by the National Science Foundation". In 1995, the federal bill for research and development at universities and colleges was $\$ 13$ billion. The ATP budget was $\$ 341$ million. Let's keep both a sense of proportion and the ATP.

Mary L. Good

(Under Secretary for Technology)

US Department of Commerce,

Washington, DC 20230, USA
Impact factors of Russian journals

SIR - According to the Journal Citation Reports $(J C R)^{1}$, the impact factor of journal $\mathrm{X}$ is defined by the following rule: "The JCR impact factor is basically a ratio between citation and citable items published. Thus, the 1988 impact factor of journal $\mathrm{X}$ would be calculated by dividing the number of all the SCI, SSCI and A\&HSCI source journals' 1988 citations of articles journal X published in 1986 and 1987 by the total number of source items it published in 1986 and 1987"'.

We should like to add to the discussion in Correspondence ${ }^{2,3}$ by pointing out the difficulties of defining the impact factors (IFs) of Russian journals. First, the list of citing/cited journals in $J C R$, as with our such indices, is not complete. There is clearly uncertainty in impact factors that is difficult to quantify. Second, inaccuracy arises from the timelag before publication of a journal. The lag can be defined as the time between submission and publication.

Consider the typical publication lag in Russia in the previous decade. In the 1980s, the IFs of Russian journals were relatively high and these may have been the most favourable years for Russian science.

In the late 1980s, publishing an article in a Russian journal became very complicated, with discussion at different seminars and commissions, mailing to the editor, printing and mailing to the libraries. Sometimes a paper has to be returned for revision. So a timelag of 1.5-2 years may not be unusual. The IFs of Russian journals at best are two to four times smaller because of the timelag.

Where Russian journals are translated, and on the assumption that the dates on the covers of the Russian English versions are the same, the timelag for citation of translated Russian journals may be much greater than that of those originally published in English.

At the beginning of the 1980 s, translation and publication in English took up to two years. This decreases the IF of the journal by a factor of four or more immediately. The same conditions do not apply now, but it seems nevertheless to be the case that the impact factors of Russian journals are undervalued.

Nikolaj I. Sorokin

Institute of Chemical

Kinetics and Combustion,

Siberian Branch,

Russian Academy of Sciences,

Novosibirsk 630090 .

Russia

1. Journal Citation Reports p.IOA (1989).

2. Nature 374, 492 (1995).

3. Nature 376, 720 (1995). 